(6) OPEN ACCESS

\title{
Five-year costs from a randomised comparison of bilateral and single internal thoracic artery grafts
}

\author{
Matthew Little, ${ }^{\oplus 1}$ Alastair Gray, ${ }^{\circ 2}$ Doug Altman, ${ }^{3}$ Umberto Benedetto, ${ }^{4}$ \\ Marcus Flather, ${ }^{5,6}$ Stephen Gerry, ${ }^{7}$ Belinda Lees, ${ }^{8}$ Jacqueline Murphy, ${ }^{\oplus 2}$ \\ Helen Campbell, ${ }^{2}$ David Taggart ${ }^{8}$
}

${ }^{1}$ Nuffield Department of

Population Health, University of Oxford, Oxford, UK

${ }^{2}$ Nuffield Department of Population Health, University of Oxford Health Economics Research Centre, Oxford, UK ${ }^{3}$ Nuffield Department of Orthopaedics, Rheumatology and Musculoskeletal Sciences, Centre for Statistics in Medicine, University of Oxford, Oxford, UK ${ }^{4}$ University of Bristol School of Clinical Science, Bristol, Bristol, UK

${ }^{5}$ University of East Anglia Faculty of Medicine and Health Sciences, Norwich, Norfolk, UK ${ }^{6}$ Norfolk and Norwich University Hospitals NHS Foundation Trust, Norwich, Norfolk, UK

${ }^{7}$ Nuffield Department of Orthopaedics, Rheumatology and Musculoskeletal Sciences, Centre for Statistics in Medicine, Oxford, UK

${ }^{8}$ Nuffield Department of Surgical Sciences, John Radcliffe Hospital Oxford, Oxfordshire, UK

\section{Correspondence to} Professor Alastair Gray; alastair.gray@dph.ox.ac.uk

Received 1 August 2018 Revised 19 January 2019 Accepted 8 February 2019 Published Online First 4 April 2019

\section{ABSTRACT \\ Background The use of bilateral internal thoracic} arteries (BITA) for coronary artery bypass grafting (CABG) may improve survival compared with $C A B G$ using single internal thoracic arteries (SITA). We assessed the longterm costs of BITA compared with SITA.

Methods Between June 2004 and December 2007, 3102 patients from 28 hospitals in seven countries were randomised to CABG surgery using BITA ( $n=1548)$ or SITA ( $n=1554)$. Detailed resource use data were collected from the initial hospital episode and annually up to 5 years. The associated costs of this resource use were assessed from a UK perspective with 5 year totals calculated for each trial arm and pre-selected patient subgroups.

Results Total costs increased by approximately $£ 1000$ annually in each arm, with no significant annual difference between trial arms. Cumulative costs per patient at 5-year follow-up remained significantly higher in the BITA group ( $£ 18$ 629) compared with the SITA group ( $£ 17$ 480; mean cost difference $f 1149,95 \% \mathrm{Cl}$ $\mathrm{f330}$ to $f 1968, p=0.006)$ due to the higher costs of the initial procedure. There were no significant differences between the trial arms in the cost associated with healthcare contacts, medication use or serious adverse events.

Conclusions Higher index costs for BITA were still present at 5-year follow-up mainly driven by the higher initial cost with no subsequent difference emerging between 1 year and 5 years of follow-up. The overall cost-effectiveness of the two procedures, to be assessed at the primary endpoint of the 10-year follow-up, will depend on composite differences in costs and qualityadjusted survival.

Trial registration number ISRCTN46552265

\section{INTRODUCTION}

Coronary artery bypass grafting $(\mathrm{CABG})$ is one of the most commonly performed operations globally and an established and effective treatment for symptomatic multivessel coronary artery disease. ${ }^{1}$ The routine surgical practice has been to graft a single internal thoracic artery (SITA) to the left anterior descending coronary artery and the use of vein or radial-artery grafts to bypass other coronary arteries. ${ }^{2}$ The excellent outcomes of SITA have stimulated interest in the use of bilateral internal thoracic arteries (BITA). ${ }^{3}$

Existing evidence from observational studies of the effect of BITA on long-term survival suggests that BITA is associated with a reduction in mortality compared with SITA. A recent meta-analysis of observational studies from nine eligible studies including 15583 patients with mean follow-up exceeding 9 years estimated a Hazard Ratio (HR) of 0.79 (95\% CI 0.75 to 0.84 ) for BITA compared with SITA. ${ }^{4}$ However, BITA has not been widely adopted due to it being a more complex procedure, associated with a higher risk of sternal wound complications and a lack of randomised evidence of benefit.

The Arterial Revascularisation Trial (ART) was designed to address these concerns, with a primary objective of comparing 10-year survival rates associated with BITA over SITA. ART has reported clinical and safety outcomes across trial arms at 5 years postrandomisation. ${ }^{5} \mathrm{CABG}$ is a high-volume procedure, with approximately 20000 carried out in England every year; therefore, it is important to consider the long-term impact on costs as well as clinical effectiveness. ART was designed with an integrated health economic evaluation and will ultimately report on the cost-effectiveness of BITA versus SITA at 10 years. A 1-year cost comparison has previously been published, showing BITA to be associated with $9 \%$ higher costs, primarily due to longer time in theatre and in-hospital stay, and slightly higher costs related to sternal wound problems during follow-up. ${ }^{6}$ However, it is possible that these differences are offset in the long run. This paper investigates this possibility by providing a comparison of resource use and costs up to 5 years postrandomisation.

\section{METHOD}

Details of the ART protocol, baseline data, 1-year safety outcomes and 5-year clinical and safety outcomes have been published previously. ${ }^{5}$ ART is a multicentre randomised control trial involving 28 hospitals across seven countries with a primary outcome of all-cause mortality at 10 years of follow-up. The trial complied with the Declaration of Helsinki. Prior ethics approval was obtained at all the participating centres and each patient was required to provide written informed consent.

Patients were eligible for the trial if they had multivessel coronary artery disease and were scheduled to undergo CABG as part of their routine care plan (this included patients requiring urgent surgery, but not those with evolving myocardial infarction). Patients requiring only single grafts or 
concomitant valve surgery, as well as those with a history of CABG, were excluded. Patients were followed up at a routine clinical visit 6 weeks postsurgery and then annually by telephone call and postal questionnaires.

\section{Measurement of resource use}

The cost analysis of the two interventional strategies followed the general methods published previously but extended the analysis to assess resource costs at the 5-year follow-up on all patients. Information was collected at each annual follow-up on medication use, subsequent sternal wound complications, serious adverse events, the frequency of visits to a general practitioner (GP), practice nurse, hospital outpatient clinic or cardiac rehabilitation clinic, and duration of any hospital readmission.

\section{Measurement of costs}

Costs were evaluated from the perspective of the English National Health Service (NHS). Clinical events and resource use during the initial hospital stay were costed using sources, methods and assumptions published previously, ${ }^{6}$ with all costs updated to $2016 / 2017$ prices using the hospital and community health services index. ${ }^{8}$ All resources used over the remaining 5 years of follow-up were costed using the appropriate 2016/2017 unit costs.

Details of the costing methodology can be found in the online supplementary material of the 1 -year analysis. ${ }^{6}$ Following this methodology, GP and practice nurse visits were costed using Personal Social Services Research Unit estimates applied to all reported visits, and NHS reference costs provided unit costs for all recorded hospital outpatient clinic and cardiac rehabilitation clinic visits. Out-of-pocket costs, such as travel costs and time spent on GP visits, were not collected as the perspective of the analysis was the healthcare system. Costs associated with the clinical events of myocardial infarction, cerebrovascular accidents, further CABG, percutaneous coronary interventions (PCI) or cardiac catheterisations were obtained from appropriate 2016/2017 NHS Reference Costs. Reference costs were adjusted for clinical events occurring during the index admission to avoid double counting. The most frequent diagnosis groups classified as 'other' included musculoskeletal, gastrointestinal, cardiac arrhythmias and genitourinary. The cost impact of these events was assumed to be captured by costing the length of stay of the admission. An emergency department attendance was assumed where participants were admitted for an event, but no overnight stay was reported. Individual drug usage was costed using unit costs from the NHS electronic Market Information Tool. Full details of the sources and assumptions used in the costings can be found in the online supplementary table 1 .

\section{Missing data}

Some items of data were missing as a result of incomplete responses or loss to follow-up. Descriptive analysis revealed that $70 \%$ of observations in each arm of the trial provided complete data for all resources used across the follow-up period. Logit models of missingness on baseline variables indicated that having some missing data was statistically significantly associated with baseline hospital, smoking status and sex. This suggests that the data are not missing completely at random as is assumed in complete case analysis. Therefore, multiple imputation was used to impute missing resource use in the trial data to limit the loss of power and bias arising from the exclusion of missing data; unit costs were then attached to the imputed resource use data.
Imputation was implemented separately by randomised treatment allocation. Missing data were imputed at the most disaggregated level at which the model would converge. Chained equations using predictive mean matching or logistic regression were used to impute missing values for each variable. ${ }^{9}$ Imputation was conducted using the baseline hospital, age, sex, baseline Canadian Cardiovascular Society (CCS) class, diabetes, smoking status and peripheral arterial disease. Following the rule of thumb that the number of imputations should be at least equal to the percentage of incomplete cases $(30 \%),{ }^{9}$ the procedure was repeated 30 times to produce 30 imputed datasets with Rubin's Rule used to summarise across imputations. ${ }^{10}$

Statistical analysis of imputed data summarised continuous data using means and categorical data using percentages. In line with recommended practice in cost analyses, ${ }^{11}$ we report mean costs, but also report median values for total costs in the online supplementary table 11 . Two-sample t-tests were used for comparisons of mean differences and 95\% CIs for differences were calculated. Standard errors were adjusted to account for clustering at the hospital level. All data analyses were performed using STATA 14.

\section{Sensitivity analyses}

The robustness of estimates to the imputation of missing data was explored by analysing the costs of a complete case sample. In addition, the robustness of estimates including only patients who received the surgery they were allocated was investigated. Uncertainty surrounding individual unit costs is not reported, as the low and multiple unit costs and infrequency of many clinical events meant that extreme changes in assumptions were required to produce even modest effects on results.

\section{Subgroup analyses}

Total annual cost at each time point and total cumulative costs were compared between BITA and SITA arms for selected pre-specified subgroups. These were: insulin-dependent diabetic, non-insulin dependent diabetic and non-diabetic, age $\geq 70$ years versus $<70$ years, on-pump versus off-pump, prior myocardial infarction versus no prior myocardial infarction, New York Heart Association (NYHA) class I and II versus NYHA class III and IV, and CCS class 0, I and II versus CCS class III and IV. Five-year costs were also compared in each of the three countries (UK, Poland and Australia) which recruited $>100$ patients to the trial.

\section{RESULTS}

Table 1 shows annual resource use and the frequency of adverse events by the two trial arms. Similar levels of resource use and counts of adverse events were observed in each trial arm at each time point. The two trial arms had similar frequencies of GP visits, nurse visits, outpatient visits, cardiac rehabilitation visits and nights in hospital at each time point. This resulted in there being no significant differences in cumulative healthcare contacts across 5 years of follow-up. Similar proportions of participants experienced an adverse event in each trial arm for the counts of myocardial infarction, cerebrovascular accident, major bleeds and deaths from any cause, whereas significantly more sternal wound problems and 'other' adverse events were reported in the BITA arm across 5 years of follow-up.

Table 2 shows the corresponding mean costs of resource use in each trial arm and by year of follow-up. No significant difference was observed for the cost of visits or hospitalisations (in total or by sub-category), or total medication usage. The only adverse 


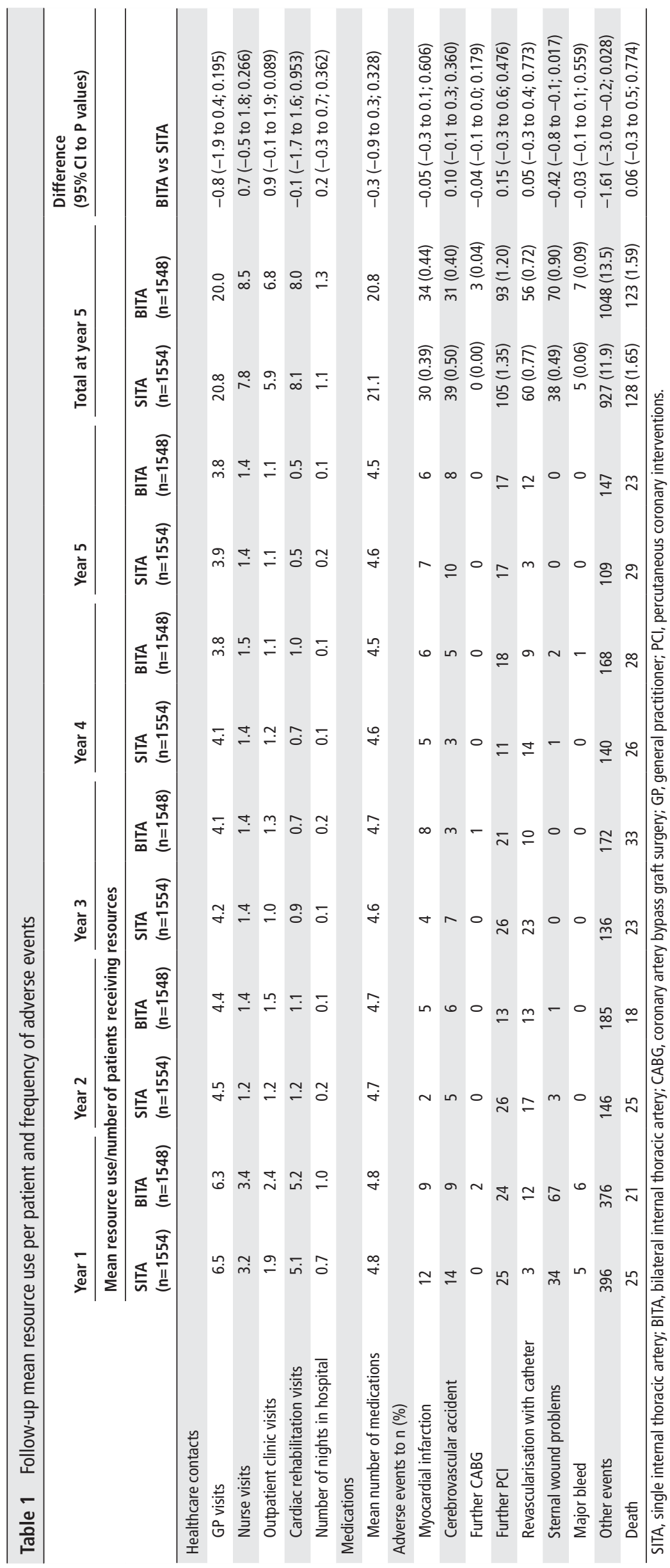




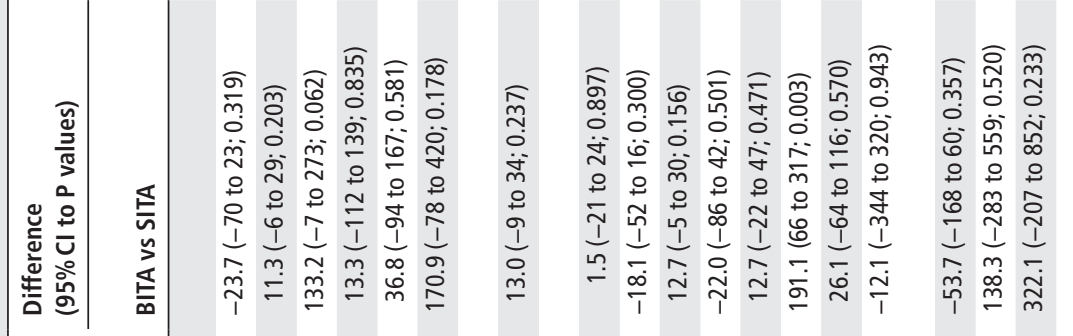

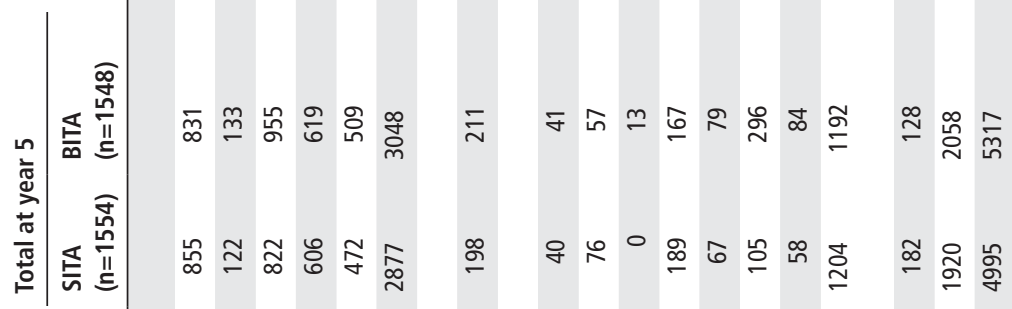

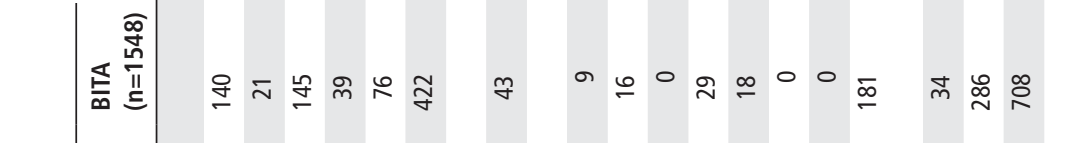

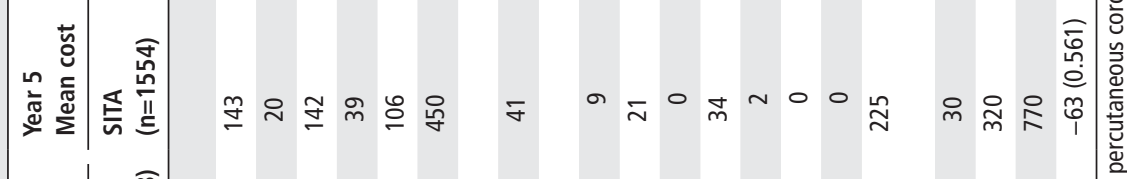

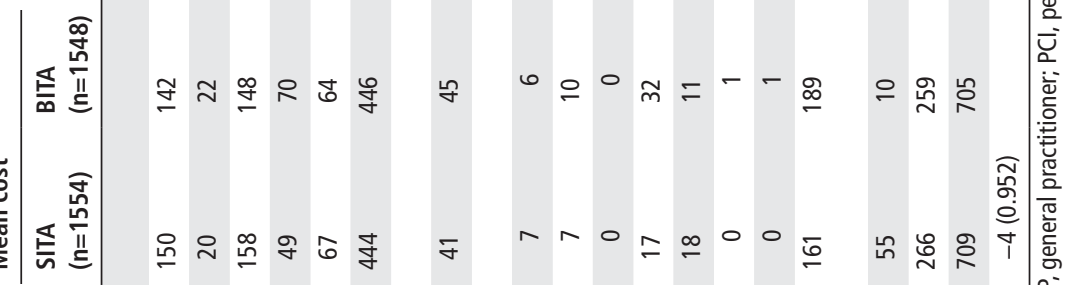

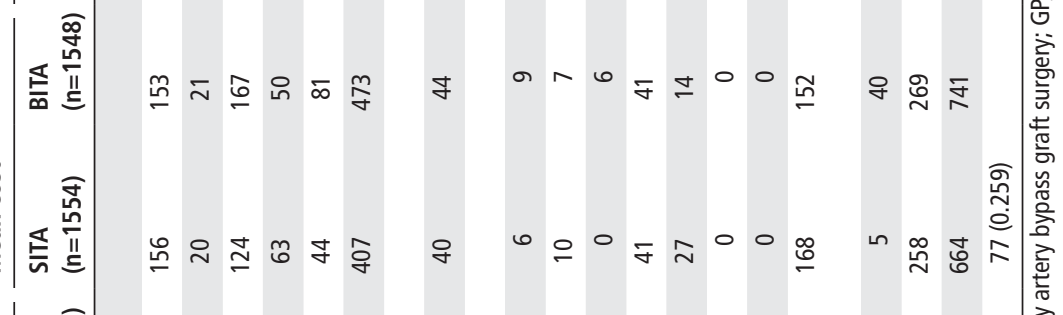

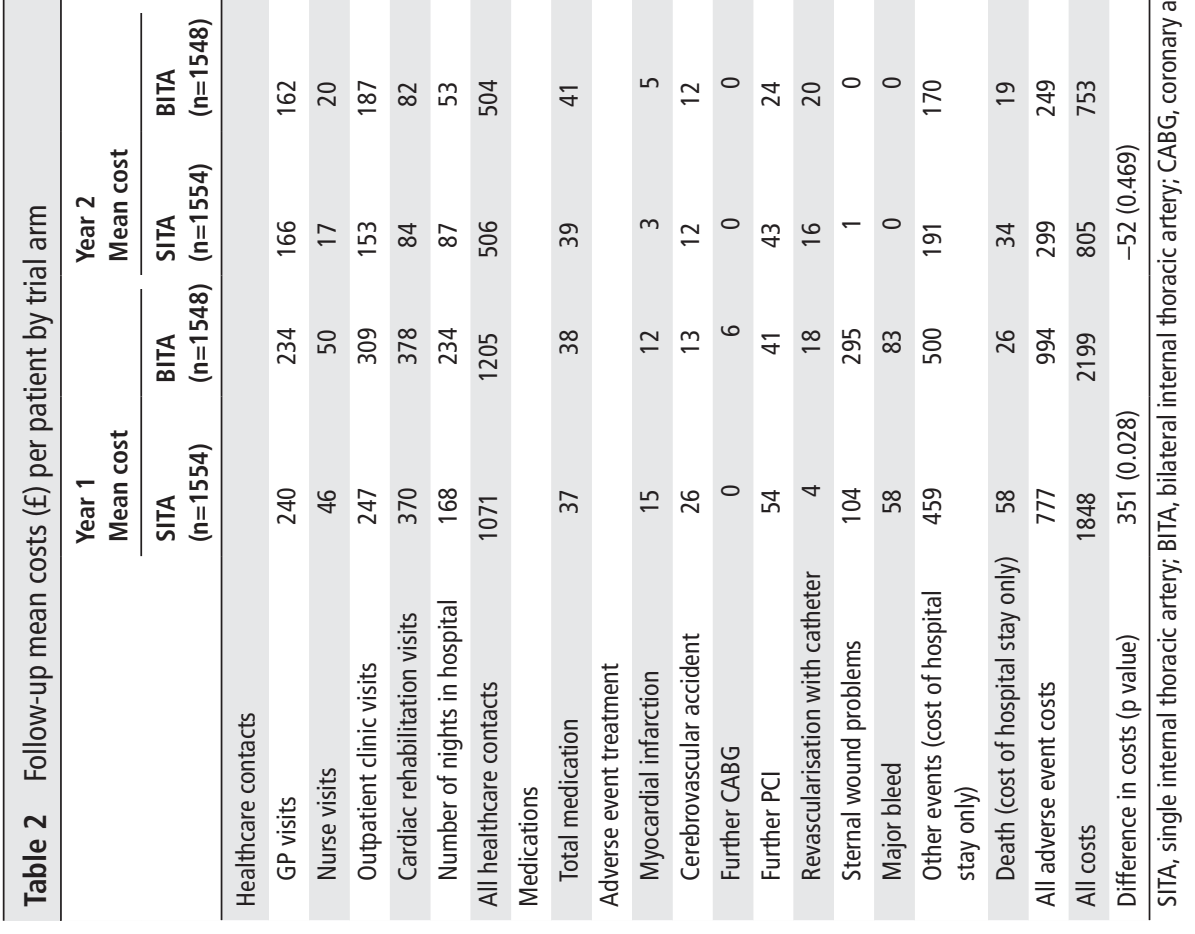


Table 3 Mean cumulative total costs ( $\mathrm{f}$ ) from index admission to the 5-year follow-up

\begin{tabular}{llll}
\hline & $\begin{array}{l}\text { SITA } \\
(\mathbf{n}=1554)\end{array}$ & $\begin{array}{l}\text { BITA } \\
(\mathbf{n}=1548)\end{array}$ & \multicolumn{1}{l}{ BITA vs SITA } \\
\hline Index & 12485 & 13312 & $827(261$ to $1392 ; 0.004)$ \\
\hline Year 1 & 14370 & 15548 & $1178(503$ to $1854 ; 0.001)$ \\
\hline Year 2 & 15214 & 16342 & $1128(419$ to $1837 ; 0.002)$ \\
\hline Year 3 & 15919 & 17127 & $1209(471$ to $1947 ; 0.001)$ \\
\hline Year 4 & 16669 & 17878 & $1209(436$ to $1981 ; 0.002)$ \\
\hline Year 5 & 17480 & 18629 & $1149(330$ to $1968 ; 0.006)$ \\
\hline
\end{tabular}

SITA, single internal thoracic artery; BITA, bilateral internal thoracic artery.

events with a significant difference in costs were sternal wound problems.

Table 3 and figure 1 show the mean cumulative costs for each year and each trial arm, and the mean difference. The index hospitalisation had a total cost of $£ 12485$ in the SITA group compared with $£ 13312$ in the BITA group with a significant difference of $£ 827$ (95\% CI $£ 261$ to $£ 1392, \mathrm{p}<0.004$ ). Annual costs increased in each arm by approximately $£ 1000$ annually, with no evidence of the mean difference that had emerged by the end of year one changing significantly over time. By year 5 , cumulative costs were on average $£ 1149$ higher in the BITA group than the SITA group $(95 \%$ CI $£ 330$ to $£ 1968$, $\mathrm{p}<0.006)$. This difference was mainly due to the higher cost of the initial procedure.

Table 4 shows total costs to the 5 -year follow-up for the various prespecified subgroup analyses and the country comparisons. The difference between the trial arms was found to vary by subgroup, with the largest differences being observed when separating patients by baseline diabetes history. Compared with the cumulative mean difference in total costs of $£ 1149$ across all patients, mean additional costs in the BITA arm were $£ 5673$ higher $(95 \% \mathrm{CI} £ 1334$ to $£ 10012, \mathrm{p}<0.011)$ for patients who were insulin-dependent, but non-significantly higher ( $£ 681$, $95 \%$ CI $-£ 227$ to $£ 1590, \mathrm{p}<0.142)$ for patients who were
Table 4 Total costs $(\mathrm{f})$ to the 5 -year follow-up by trial arm and by subgroups

\begin{tabular}{|c|c|c|c|}
\hline & $\begin{array}{l}\text { SITA } \\
\text { Mean } \\
\text { cost }\end{array}$ & $\begin{array}{l}\text { BITA } \\
\text { Mean } \\
\text { cost }\end{array}$ & $\begin{array}{l}\text { BITA vs SITA } \\
\text { Mean difference }(95 \% \mathrm{Cl} \text { to } \\
P \text { values })\end{array}$ \\
\hline $\begin{array}{l}\text { No history of diabetes } \\
(n=2368)\end{array}$ & 17269 & 17951 & 681 (-227 to $1590 ; 0.142)$ \\
\hline $\begin{array}{l}\text { Insulin-dependent diabetes } \\
(n=174)\end{array}$ & 18355 & 24028 & $5673(1334$ to $10012 ; 0.011)$ \\
\hline $\begin{array}{l}\text { Non-insulin-dependent } \\
\text { diabetes }(n=560)\end{array}$ & 17957 & 19403 & $1447(-474$ to $3367 ; 0.140)$ \\
\hline Aged $<70$ years $(n=2271)$ & 16474 & 17842 & 1368 (538 to $2198 ; 0.001)$ \\
\hline Aged $\geq 70$ years $(n=831)$ & 20042 & 20666 & $623(-1398$ to $2644 ; 0.545)$ \\
\hline Off-pump ( $n=1259)$ & 17905 & 18065 & $160(-1237$ to $1557 ; 0.823)$ \\
\hline On-pump ( $n=1819$ ) & 17256 & 19214 & 1958 (985 to $2931 ; 0.000)$ \\
\hline No prior MI $(n=1800)$ & 17222 & 18088 & $866(-150$ to $1882 ; 0.095)$ \\
\hline Prior MI $(n=1300)$ & 17746 & 19260 & 1514 (187 to $2840 ; 0.025)$ \\
\hline $\begin{array}{l}\text { NYHA class I and II } \\
(n=2431)\end{array}$ & 17556 & 18296 & $740(-132$ to $1612 ; 0.096)$ \\
\hline $\begin{array}{l}\text { NYHA class III and IV } \\
(\mathrm{n}=669)\end{array}$ & 17039 & 19582 & 2542 (534 to $4550 ; 0.013$ ) \\
\hline CCS class 0 to I, II $(n=2143)$ & 17571 & 18185 & $614(-347$ to $1575 ; 0.210)$ \\
\hline $\begin{array}{l}\text { CCS class III to IVa/b/c } \\
(\mathrm{n}=959)\end{array}$ & 17175 & 19452 & 2278 (769 to $3786 ; 0.003)$ \\
\hline UK $(n=2053)$ & 18052 & 18864 & 813 (-306 to $1932 ; 0.154)$ \\
\hline Poland $(n=606)$ & 15691 & 16811 & 1120 (130 to $2109 ; 0.027)$ \\
\hline Australia ( $n=192$ ) & 19878 & 21767 & $1889(-682$ to $4460 ; 0.149)$ \\
\hline
\end{tabular}

without diabetes. Figure 2 shows how these differences evolved over the first 5 years of the trial. Table 4 also shows that differences in costs between the trial arms were somewhat larger for patients with a history of myocardial infarction, more severe angina or cardiac disease compared with those with no history, for on-pump compared with off-pump patients, for CCS class

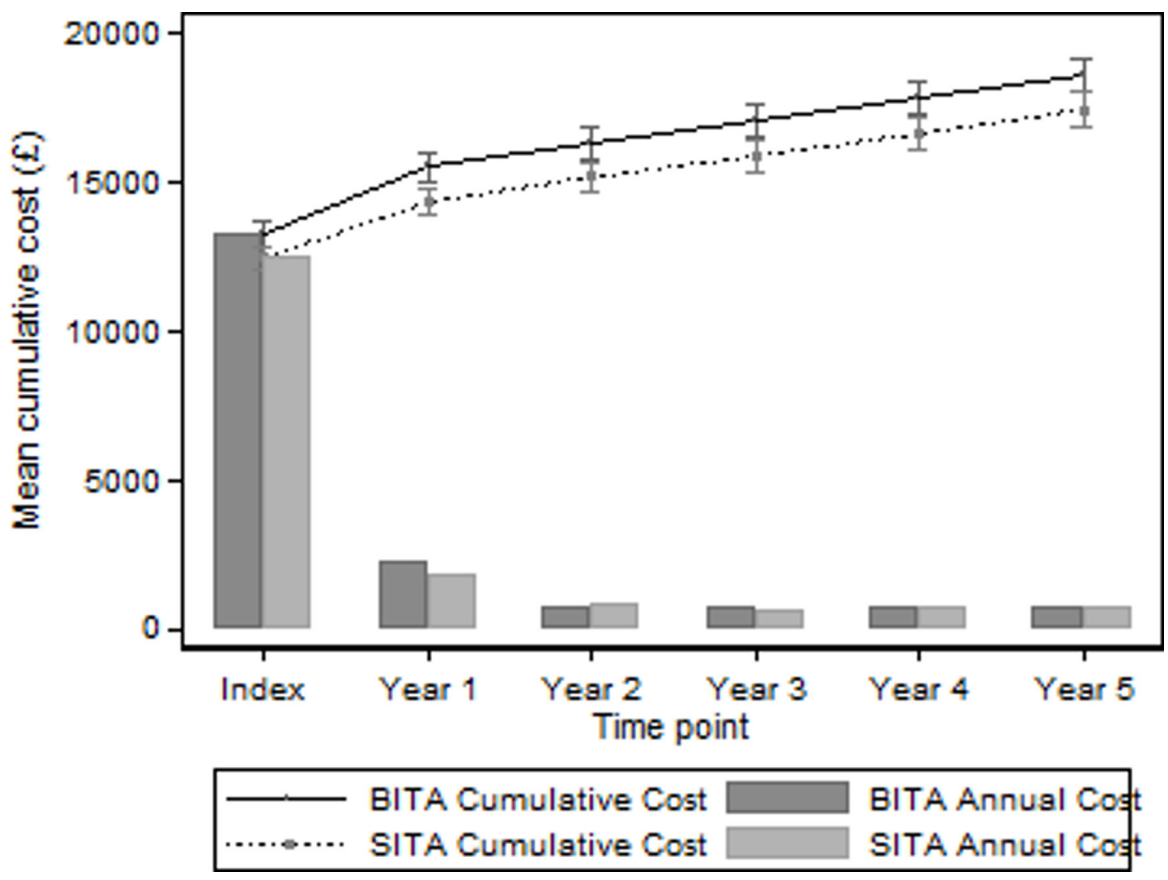

Figure 1 Mean cumulative total cost and mean annual follow-up costs. 


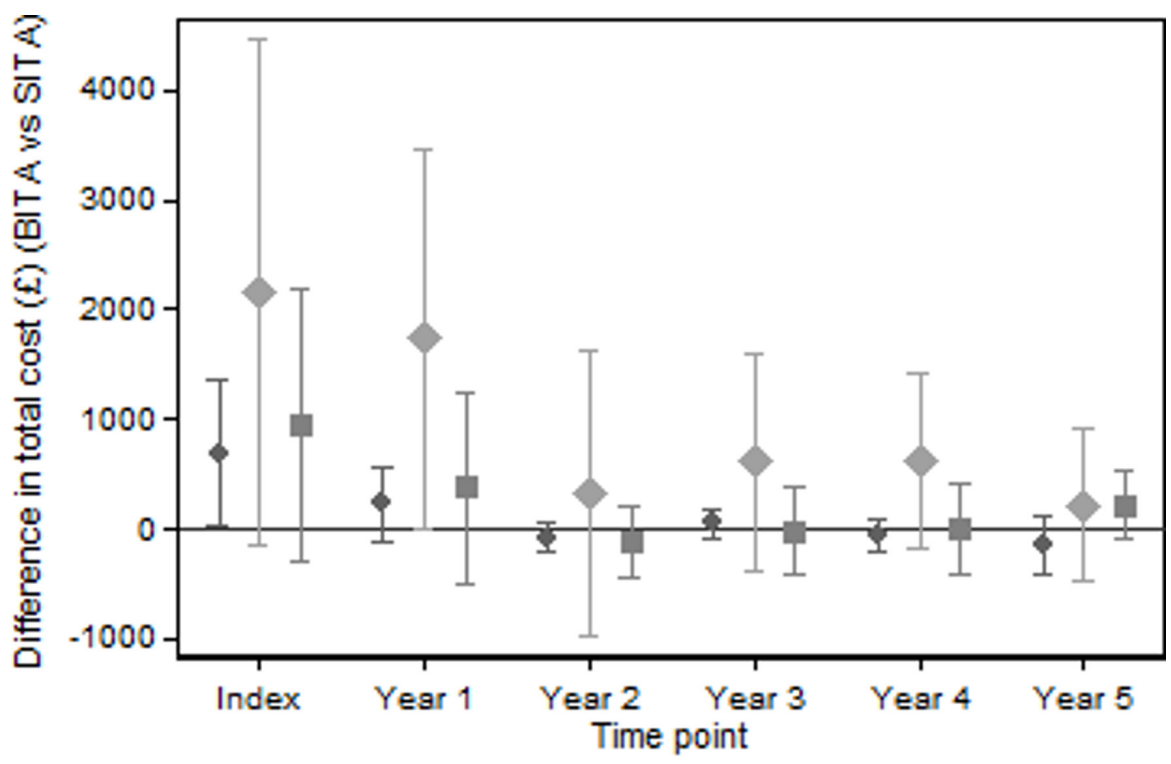

No history of diabetes $>$ Insulin dependert
Non-insulin dependent

Figure 2 Differences in mean total costs (BITA vs SITA, 95\% CI) by baseline history of diabetes over time. BITA, bilateral internal thoracic artery; SITA, single internal thoracic artery.

III and above compared with class 0 , I and II, and for patients in Australia. Full details of the difference between trial arms by subgroup are provided in the online supplementary tables 4-10 and figures 1-6.

\section{DISCUSSION}

ART is the first and largest randomised comparison of SITA and BITA ever conducted and has permitted the first detailed comparison of costs of these procedures over a 5 -year period. We found the significantly higher index cost of BITA ( $£ 827$, 95\% CI $£ 261$ to $£ 1392$ ) is maintained up to the 5-year follow-up as a result of similar total costs observed in each arm over each subsequent follow-up period.

This is the first study to compare the cost of BITA and SITA at 5 years postsurgery. The finding of similar total costs following the initial procedure over a 5 -year period is in contrast to previous studies comparing the cost-effectiveness of CABG and PCI, which have found differences in costs to emerge over a similar length of time. Evidence from the SYNTAX trial, for example, found that an initial difference of about $\$ 10000$ post index admission reduced to $\$ 5600$ after 5 years of follow-up due lower revascularisation rates and medication usage in the CABG group. ${ }^{12}$ It is possible that differences between BITA and SITA may eventually emerge due to the superior long-term graft patency achieved with arterial grafts.

Higher cumulative costs of BITA compared with SITA at 5 years were found to be particularly marked in patients who were insulin-dependent compared with those who were non-insulin dependent or were without diabetes. The online supplementary table 4 shows that this difference was primarily driven by higher outpatient costs, longer stays in hospital and costs associated with sternal wound problems, which are well recognised to be more frequent in patients with diabetes. Indeed, several observational studies have found diabetes and BITA to be independent risk factors for sternal wound infections following CABG. ${ }^{13} 14$ However, a recent observational study found BITA to only be an independent predictor in patients with chronic complications of diabetes mellitus. ${ }^{15}$

Differences in costs also varied by surgical technique, with higher mean total costs observed for BITA patients who underwent on-pump CABG while no significant difference was observed for patients who underwent off-pump CABG. This difference in costs was primarily driven by the higher cost of the index admission of BITA patients who underwent on-pump CABG. This finding compliments those of CORONARY (the CABG off or On Pump Revascularization Study), which showed no significant difference in 5-year total costs (mean difference $\$ 115,95 \%$ CI $-\$ 697$ to $\$ 927$ ) between patients who underwent off-pump or on-pump CABG. ${ }^{16}$

The analysis in this paper is based on the randomised comparison of BITA and SITA ever conducted, which reduces the potential of bias arising from unobserved factors. Our findings are in contrast to a recent retrospective study comparing BITA and SITA using a large US observational sample, which found lower costs for BITA and a shorter length of stay during the index admission. ${ }^{15}$ These differences may be the result of bias arising from unobserved heterogeneity between patients in the non-randomised study.

The analysis in this paper assumed missing data to be MAR with predictions based on the resource use of similar patients without missing data. It is not possible to validate this assumption; however, sensitivity analysis can explore how the results are affected if data were assumed to be missing not at random. Following the recommendation of Faria et al, ${ }^{17}$ this was achieved by shifting imputed data by a sensitivity parameter to give a dataset imputed under MNAR. The included values of the sensitivity parameter varied imputed costs between $-30 \%$ and $30 \%$ at $5 \%$ point intervals. The results from this analysis are shown in the online supplementary figure 9, which found that the difference in mean cost at the 5 -year follow-up varied between $£ 950$ and $£ 1350$. 
A potential limitation of the current analysis was the application of UK-based unit costs to resource use from seven countries. This could systematically misestimate total costs if differences in relative prices between countries have resulted in systematically different patterns of resource use. However, such an effect would not necessarily bias the randomised comparison. The data and results presented here should permit analysts to conduct analyses from the perspective of countries other than the UK using appropriate local unit cost sets.

\section{CONCLUSION}

The higher initial costs of BITA compared with SITA were still present at the 5-year follow-up, with similar levels of resource use each year following the index procedure. Other differences may emerge by the time all patients reach the 10-year follow-up, the relevant time-point for the primary outcome of the trial. Finally, in order to assess the cost-effectiveness of BITA versus SITA, any differences in cost will have to be viewed alongside any differences in quality-adjusted survival, which will be reported at the 10 -year follow-up.

\section{Key message}

\section{What is already known on this subject?}

- The use of a single internal thoracic artery (SITA) for coronary artery bypass grafting is a safe, effective and high-volume procedure, but bilateral internal thoracic arteries (BITA) may offer improved long-term patient outcomes.

\section{What might this study add?}

- No randomised comparison of the long-term costs of these procedures has previously been published. Using data from the Arterial Revascularisation Trial, we showed that the higher index costs of BITA were still present at the 5-year follow-up mainly driven by the higher initial cost with no subsequent difference emerging between 1 year and 5 years of followup. Larger differences were observed in certain patient subgroups, particularly diabetes versus non-diabetes.

\section{How might this impact on clinical practice?}

- Clinicians and healthcare policy-makers will find our results of value when considering the potential cost implications of moving from SITA to BITA. These cost estimates will also be required for researchers to assess the long-term costeffectiveness of BITA.

Acknowledgements The authors thank all the patients who are participating in this trial in the seven countries worldwide; the investigators at the participating centres, the members of the steering committee, data and safety monitoring committee, and the clinical-events adjudicators, Dr Jeremy Pearson (British Heart Foundation) and Dr Mark Pitman (UK Medical Research Council), for support throughout; Emma Haines, Sarah Dutton and Edmund Wyatt, Surgical Intervention Trials Unit, University of Oxford, Oxford, UK and the late Ms Eva Matesanz, Mr Wajid Aslam and Ms Fiona Nugara, Clinical Trials and Evaluation Unit, Royal Brompton and Harefield NHS Foundation Trust, London, UK for data co-ordination and management; Professor Lukasz Krzych, Medical University of Silesia, Katowice,
Poland for help in co-ordinating and managing the trial in Poland; Dr Surjeet Singh and Mr Damien Hayward, Surgical Intervention Trials Unit, University of Oxford, Oxford, UK for trial support.

Contributors ML: drafted the manuscript and conduced the data analysis based on previous work by JM and HC. AG: designed and led the economic analysis. DT: conceived and leads the ART Trial and is principal investigator. SG: provided statistical expertise and analysis. DA, UB, HC, MF, SG, BL and DT: contributed to refinement of this study and commented on drafts of the manuscript. All authors approved the final manuscript

Funding This work was supported by the British Heart Foundation (SP/03/001), the UK Medical Research Council (G0200390), and the National Institute of Health Research Efficacy and Mechanism Evaluation Programme (09/800/29).

\section{Competing interests None declared.}

Provenance and peer review Not commissioned; externally peer reviewed.

Open access This is an open access article distributed in accordance with the Creative Commons Attribution 4.0 Unported (CC BY 4.0) license, which permits others to copy, redistribute, remix, transform and build upon this work for any purpose, provided the original work is properly cited, a link to the licence is given, and indication of whether changes were made. See: https://creativecommons.org/ licenses/by/4.0/.

\section{REFERENCES}

1 Taggart DP. Thomas B. Ferguson Lecture. Coronary artery bypass grafting is still the best treatment for multivessel and left main disease, but patients need to know. Ann Thorac Surg 2006:82:1966-75.

2 Aldea GS, Bakaeen FG, Pal J, et al. The Society of Thoracic Surgeons Clinical Practice Guidelines on Arterial Conduits for Coronary Artery Bypass Grafting. Ann Thorac Surg 2016;101:801-9.

3 Glineur D, Papadatos S, Grau JB, et al. Complete myocardial revascularization using only bilateral internal thoracic arteries provides a low-risk and durable 10-year clinical outcome. Eur J Cardiothorac Surg 2016;50:735-41.

$4 \mathrm{Yi} \mathrm{G}$, Shine B, Rehman SM, et al. Effect of bilateral internal mammary artery grafts on long-term survival: a meta-analysis approach. Circulation 2014;130:539-45.

5 Taggart DP, Altman DG, Gray AM, et al. Randomized Trial of Bilateral versus Single Internal-Thoracic-Artery Grafts. N Engl J Med 2016;375:2540-9.

6 Gray AM, Murphy J, Altman DG, et al. One-year costs of bilateral or single internal mammary grafts in the Arterial Revascularisation Trial. Heart 2017;103:1719-26.

7 Taggart DP, Lees B, Gray A, et al. Protocol for the Arterial Revascularisation Trial (ART). A randomised trial to compare survival following bilateral versus single internal mammary grafting in coronary revascularisation Trials 2006:7:7.

8 Curtis LA, Burns A. Unit Costs of Health and Social Care: In. Personal Social Services Research Unit. Canterbury: University of Kent, 2017.

9 White IR, Horton NJ, Carpenter J, et al. Strategy for intention to treat analysis in randomised trials with missing outcome data. BMJ 2011;342:d40.

10 Rubin DB. Multiple imputation for nonresponse in surveys: John Wiley \& Sons, 2004

11 Husereau D, Drummond M, Petrou S, et al. Consolidated Health Economic Evaluation Reporting Standards (CHEERS) statement. BMJ: British Medical Journal 2013:346.

12 Cohen DJ, Osnabrugge RL, Magnuson EA, et al. Cost-effectiveness of percutaneous coronary intervention with drug-eluting stents versus bypass surgery for patients with 3-vessel or left main coronary artery disease: final results from the Synergy Between Percutaneous Coronary Intervention With TAXUS and Cardiac Surgery (SYNTAX) trial. Circulation 2014;130:1146-57.

13 Nakano J, Okabayashi $\mathrm{H}$, Hanyu $\mathrm{M}$, et al. Risk factors for wound infection after offpump coronary artery bypass grafting: should bilateral internal thoracic arteries be harvested in patients with diabetes? J Thorac Cardiovasc Surg 2008:135:540-5.

14 Deo SV, Shah IK, Dunlay SM, et al. Bilateral internal thoracic artery harvest and deep sternal wound infection in diabetic patients. Ann Thorac Surg 2013;95:862-9.

15 Itagaki S, Cavallaro P, Adams DH, et al. Bilateral internal mammary artery grafts, mortality and morbidity: an analysis of 1526360 coronary bypass operations. Heart 2013:99:849-53

16 Lamy A, Devereaux PJ, Prabhakaran D, et al. Five-Year Outcomes after Off-Pump or On-Pump Coronary-Artery Bypass Grafting. N Engl J Med 2016;375:2359-68.

17 Faria R, Gomes M, Epstein D, et al. A guide to handling missing data in cost-effectiveness analysis conducted within randomised controlled trials. Pharmacoeconomics 2014;32:1157-70. 